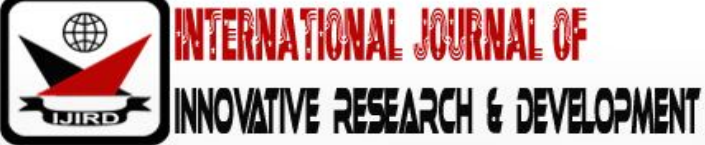

ISSN 2278 - 0211 (Online)

\section{The Effects of Drought on the Livelihood of Rural Households in the Nandom District of the Upper West Region, Ghana}

\author{
Philip Awosi \\ Part Time Lecturer, University of Cape Coast, Tamale Campus \& Teacher, \\ Business Senior High School, Tamale, Ghana \\ Dr. Isaac Agyemang \\ Senior Lecturer, University for Development Studies, \\ Abdul-Basit Danjoe Munkaila \\ Part Time Lecturer, University of Ghana and University of Education, Tamale Campuses, Ghana
}

\begin{abstract}
:
Drought is considered the most threatening component of climate change and its impact is much felt in societies where there is heavy dependence on natural environment and its resources for survival with low coping strategies. The study examines the effects of drought on the livelihood of rural households and their coping strategies in the Nandom District of Upper East Region of Ghana. Descriptive research design was applied in the study. Questionnaire was the main tool used to collect empirical data. The data was analysed quantitatively. The data were presented in the form of tables and graphs with the use of Statistical Package for Social Scientists (SPSS) software and Microsoft Excel. The results indicate that droughts experienced overtime in the district have devastating effects on the livelihood of rural households. Households resort to low paid jobs, migration, pito brewing, societal support systems, fuel wood and charcoal burning to cope with drought. The study concludes that drought is a real phenomenon in the study area. The study recommends that integrated approaches must be adopted to tackle the problem of drought both in the short-run and in the long-run.
\end{abstract}

Keywords: Drought, climate change, livelihood

\section{Introduction}

Globally, the negative impacts of climate change are becoming increasingly evident today, including long term changes in average temperature and rainfall, changes in the intensity, timing, and geographic distribution of rainfall, an increase in the rate at which extreme events such as drought and flood, and sea level rise (IPCC, 2007; Verner, 2011). These impacts will have detrimental effects on agricultural productivity, biodiversity and ecosystem services. Although some crops in some regions of the world may experience gains, however, research by Keane, Page, Kergna, and Kennan (2009) and Nelson (2010) predict that the overall impacts of climate change on agriculture will be negative, threatening global food security.

In Africa, climate change has affected the rainfall pattern such that longer and more persistent drought periods are being experienced (IPPC, 2007). Drought has a negative impact on agricultural activities which are the mainstay of most rural people in Africa south of the Sahara. The severity of the impact of drought on African farmers was underscored by the Intergovernmental Panel on Climate Change (IPCC, 2007: 435) when the panel pointed out that although "African farmers have developed several adaptation options to cope with current climate variability (example drought) such adaptations may not be sufficient for future changes of climate." All African farmers suffer the consequences of climate change, but the rural poor are more affected because their livelihoods almost entirely depend on agricultural activities. Hendy (2001), maintained that northern Kenya experiences drought periodically which affects crop production, and Little (2006) added that drought negatively affects livestock production among the poor in Ethiopia.

While the frequent occurrence of drought as a result of climate change is well documented, the effects of drought on rural households have not been included (Dankelman, 2008; IPCC, 2007). Mohammed (2013), contended that in the case of Ghana very little has been done aimed at assessing the interrelationship of the occurrence of droughts on assets holding and their consequential impact on agricultural and energy activities that may affect the livelihood of the rural dweller. Such information will fill the knowledge gap of which great significance will be put to droughts effects in the planning and management of water resources. This study therefore assesses the impact of droughts on rural dwellers. The research also highlights the indigenous management strategies during droughts and the effect of the coping strategies adopted on their workloads. According to Alfredo (2007), the livelihood of the people of Nandom District before and after the 2007 droughts seems to suggest a downward trend in the general well-being and depletion of the assets of the inhabitants. This is subject to investigation. 


\subsection{Problem Statement}

Rural communities of developing countries have historically been challenged with the lack of infrastructure and social services due to harsh economic conditions. Northern Ghana which is largely rural is noted for its persistent harsh economic conditions (Long, 1977).

The notable industry that has engaged majority of the youth and the general populace in the northern parts of Ghana is agriculture mainly due to the abundance of arable land (FAO, 2011). Agriculture offers many opportunities to the people of the north, men and women alike, and Ghana as a whole. The agricultural industry has always been underexploited. This means that the agricultural industry contributes less when it comes to supporting the economic growth of the north and the subsequent arrest of the food insecurity across the country especially during the lean season when almost all food stuffs become scarce across the West African Sub-Region (FAO, 2011).

The Nandom District has experienced some interventions in the form of relief and coping strategies by government and non-governmental organisations, with some research work done on the impact of climate change on the lives of rural households. For instance, the impact of irrigation dam interventions on the livelihoods of farmers in the Upper West Region by Lingnule (2010). There is little information on the effects of drought on the livelihood of rural households, and their coping strategies in the Nandom District. It is within this context that this study examines the effects of drought on the livelihood of rural households in the Nandom District.

\section{Literature Review}

\subsection{Drought as a Natural Hazard}

Bryant (1991), ranked hazard events based on their characteristics and impacts. Key hazard characteristics used for ranking included the degree of severity, the length of event, total areal extent, total loss of life, total economic loss, social effect, long-term impact, suddenness, and occurrence of associated hazards. It was found that drought stood first based on most of the hazard characteristics. Other natural hazards, which followed droughts in terms of their rank, are tropical cyclones, regional floods, earthquakes, and volcanoes (Bryant, 1991).

\subsection{Adaptation and Coping Strategies of Drought}

Adaptation to drought and other components of climate change includes all adjustments in behaviour or economic structure that reduce the vulnerability of society to changes in the climate system (Smith, Burton, Klein \& Street, 1999). Adaptation takes place at all levels, from changes in global systems through changes at national or regional levels to adaptations made by local communities and individuals. The development of adaptation strategies needs to recognize this and define the appropriate mix of actions at these different levels (Smith, Burton, Klein \& Street, 1999).

One key role for adaptation and the reduction of such vulnerabilities hold according to Ellis (2000), the diversification of livelihoods. The diversification of rural livelihoods is defined as the process by which rural households construct an increasingly diverse portfolio of activities and assets in order to survive and to raise their standard of living (Ellis, 2000). The increase of a livelihood portfolio, in other words, the attempt to multiply the sources of income like off-farm labour, remittances from migration stays, etc., might be an outcome of a livelihood adaptation process, but diversification is not necessarily the only way of adaptation. Intensification, which is referring to existing income sources that are used more intensively to guarantee a higher income, is another option (Ellis, 2000).

It is worth acknowledging that there is a general rise in temperature level due to drought as revealed by literature for this research work. The impacts of drought have affected livelihoods in so many ways and continue to pose challenges to developmental goals and objectives. Despite these challenges, rural households are mostly adopting several strategies to cope with these changes (Ellis, 2000). agricultural economic activities in the Nandom District are a justification to this assertion.

\section{Methodology}

The study adopted the descriptive research design by employing both qualitative and quantitative designs. Data collection sources entailed primary and secondary sources. The study population comprised of selected households, meteorological officers, assembly members. The sample size for the survey was 100 household respondents. Justifiably, the sample size chosen was highly dependent on the stipulated period of time, the size of the district, the number of communities in the district, the estimated number of households in each rural community, and also to meet general social research practices. The study employed simple random, and purposive sampling techniques to select respondents for the study. Questionnaire was used to gather the data for the study. The data collected were statistically analysed using SPSS and MS Excel. A presentation in the form of tables and charts were used to ensure easy interpretation of the data.

\section{Data Analyses and Results}

The study determines how drought affects the livelihoods of rural households in the Nandom District of the Upper West Region. In order to ensure comprehensive and logical output, this paper presents the findings of the study in sections. The first part contains trend analysis of available data on climatic factors and the impact of drought on the livelihood of rural households in the Nandom District. Section two investigates the effects of drought on assets collection and the coping strategies adopted by the rural poor during drought periods in the Nandom District of the Upper West Region, Ghana. 


\subsection{Rainfall Trends in the Nandom District from 2011 to 2013}

Figure 1 shows meteorological data of rainfall pattern which indicate the trends in climatic conditions and occurrence of extreme climatic events (in this case drought) in the district. Generally, the amount of rainfall on annual basis has been undulating. Some of the cases that are much pronounced and still fresh in the minds of respondents is the 1982/ 83 drought which devastated livelihoods and compelled people to feed on many plants and animals that were traditionally branded as taboo. The large fluctuations in rainfall between 2011 and 2013 explain that drought could happen in a particular year and excessive rainfall in another year. Coping strategies to these instances are lesser as adaptation is one sided with support from social networks such as the extended family system. All livelihood options that could not cope with these disasters were affected worsening their vulnerability and weakening the coping strategies of the already vulnerable (women, children, peasant farmers, the aged, landless people).

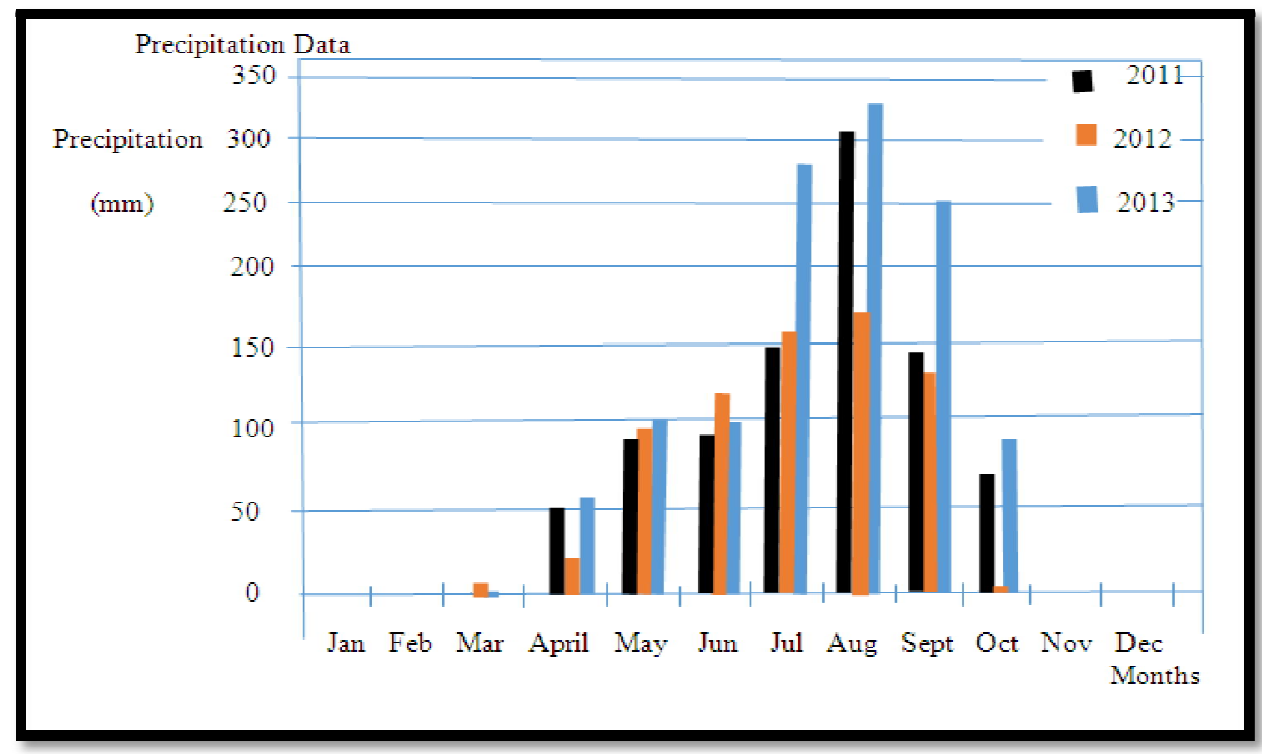

Figure 1: Precipitation Trend for Three Years (2011 - 2013)

Source: Ghana Meteorological Service Department (Wa), 2014

\subsection{Temperature Trends in the Nandom District from 2011 to 2015}

Temperature indicates a seemingly negligible and unnoticeable but there has been a gradual increase in temperature levels with some fluctuations between 2011 and 2015 as shown in table 4.1. This observation also reflects yearly recordings for each month. The temperature levels have strong correlation with rainfall and to a large extent determinant of planting season for specific crop types to engineer proper maturity and good harvest.

The gradual increase in temperature levels also means that livelihood options should be resistant to high temperatures. High temperatures are believed by the local people of Nandom District to promote good fruition of the Shea trees which is an advantage to women who are largely into picking, processing and selling of Shea nuts.

\begin{tabular}{|c|c|c|c|c|c|c|c|c|c|c|c|c|c|}
\hline Year & Jan & Feb & March & April & May & June & July & Aug. & Sept. & Oct. & Nov. & Dec. & Annual \\
\hline 2011 & 28.1 & 29.5 & 31.7 & 30.9 & 27.7 & 27.7 & 25.9 & 25.1 & 25.2 & 27.8 & 27.9 & 26.9 & 27.9 \\
\hline 2012 & 28.5 & 31.4 & 31.3 & 30.5 & 26.6 & 27.9 & 26.1 & 25.6 & 26.5 & 27.3 & 27.5 & 25.3 & 27.9 \\
\hline 2013 & 27.2 & 28.9 & 31.2 & 31.3 & 29.3 & 27.5 & 25.9 & 25.8 & 26.3 & 28.5 & 29.3 & 28.4 & 28.3 \\
\hline 2014 & 28.6 & 27.7 & 31.3 & 30.8 & 29.0 & 27.1 & 26.2 & 26.1 & 26.0 & 27.7 & 29.1 & 27.1 & 28.1 \\
\hline 2015 & 29.0 & 31.8 & 32.9 & 31.2 & 29.6 & 28.2 & 27.0 & 26.4 & 26.4 & 27.5 & 29.3 & 28.0 & 28.9 \\
\hline
\end{tabular}

Table 1: Five Year Mean Monthly Temperatures (Degree Celsius, 2011 - 2015)

Source: Ghana Meteorological Service Department (Wa), 2015

A critical examination of table 4.1 above shows that temperatures increased gradually from 2011 to 2015 with some fluctuations in the monthly temperatures. This greatly influenced the duration and intensity of drought in the study area as high temperatures sometimes triggers drought situations.

\subsection{Effects of Drought on Assets Collection}

\subsubsection{Main Household Occupation}

As captured in table 4.2, the main household occupation of the people of Nandom is farming 61.0 percent with few of them engaging in trading 23.0 percent, government 7.0 percent work and other livelihood supporting activities such as pito brewing, handicraft, carpentry, masonry comprising of 9.0 percent. A closer look at the gender disaggregated figures reveals that most of the people who indicated that they are farmers are men. Of the 44 men respondents, 34 that is 34.0 percent are into farming as their main occupation. 7 that is 7.0 percent are engaged in trading whiles 3 that is 3.0 percent are government workers. This contrasts sharply with the female respondents who have 27.0 percent of them 
engaged in farming, 16.0 percent in trading, 4.0 percent being government workers, and 9.0 percent into others activities to earn a living.

\begin{tabular}{|c|c|c|c|}
\hline \multirow{2}{*}{ Main Occupation } & \multicolumn{2}{|c|}{ Sex of Respondent } & \multirow{2}{*}{ Total } \\
\cline { 2 - 3 } & Male & Female & \\
\hline Farming & 34.0 & 27.0 & 61.0 \\
Trading & 7.0 & 16.0 & 23.0 \\
Government & 3.0 & 4.0 & 7.0 \\
worker & 0.0 & 9.0 & 9.0 \\
Others & 44.0 & 56.0 & 100.0 \\
Total & & & \\
\hline
\end{tabular}

Table 2: Household Occupation and Sex of Respondents

Source: Awosi, Agyemang \& Munkaila (2018)

\subsubsection{Easiness of Collecting Assets during Drought and Non-Drought Periods}

On the issue of easiness of collection of assets during drought and non-drought periods, the study revealed that 71 percent of the respondents said it was difficult to collect assets during drought periods and 28 percent said it was very difficult to do same in such periods whiles 1 percent said it was easy for them. The bottom line here is that it is not easy to collect these valuable assets (natural, physical, financial, and social) during drought periods. However, respondents were quick to add that it was not very difficult gathering these same assets during non-drought periods.

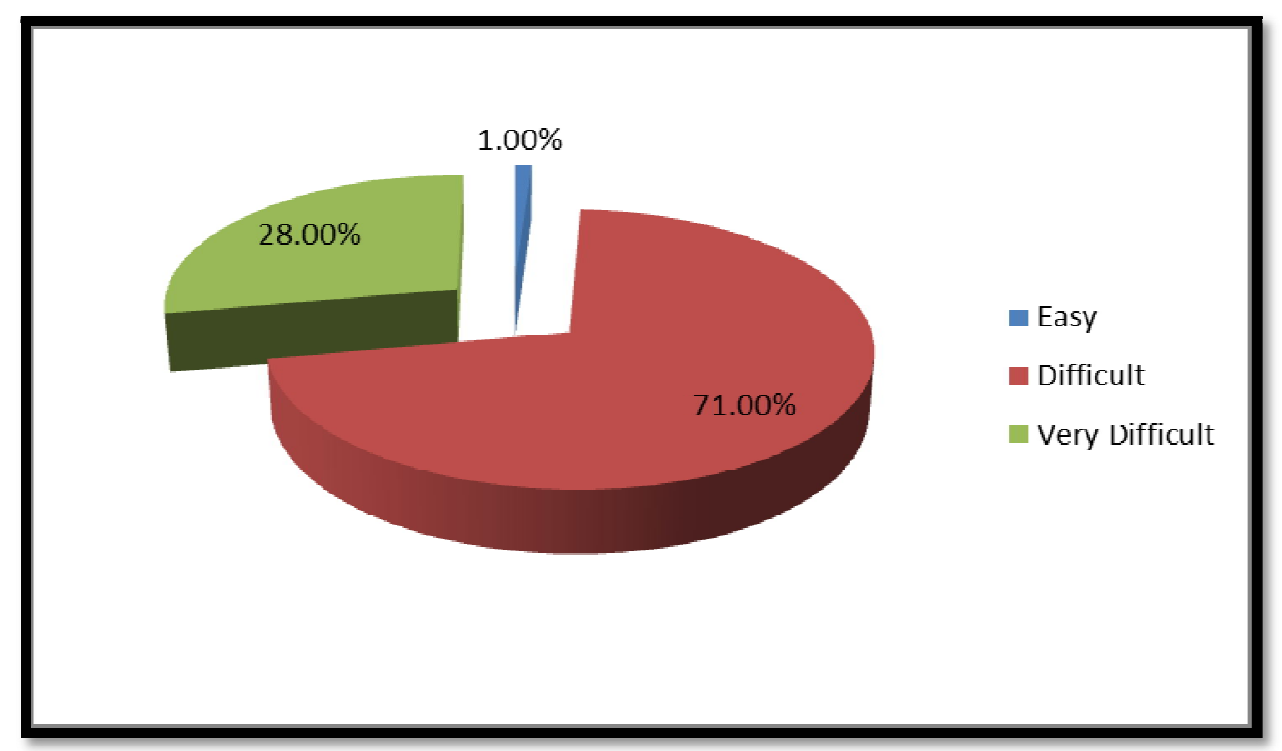

Figure 2: How Easy Is It to Collect Assets during Drought Periods Source: (Awosi Etc Al., 2018)

\subsection{Coping Strategies Adopted by Rural Households during Drought Periods}

Coping strategies are important component of this research. This area will thus focus on whether or not one work during drought periods, type of work done during drought period, causes of drought, local early warning signals of drought, assessment of droughts over the years, reasons (if any) for drought changes over time, effects of changes in drought on respondents' livelihood and copying strategies of respondents during drought periods, livelihood resilience during drought periods, and ultimately how drought affects the well-being of respondents.

\subsection{How Drought Affects the Livelihood of Respondents}

On the issue of how drought affects the livelihood of the people. Data from table 4.3, shows that 59.0 percent of the respondents indicated that the drought periods increase their poverty levels. 27 percent said it lowers their standard of living and 11 percent said it worsen their poverty levels. Farming which is the main occupation of the people comes to a standstill with the onset of drought since irrigational facilities are unavailable for dry season farming. Respondents said they have to sell off assets to maintain diet levels and majority 65.0 percent of them who did not have assets to sell had their livelihoods negatively affected greatly.

\begin{tabular}{|c|c|c|}
\hline Effect & Frequency & Percentage \\
\hline Low standard of living & 21 & 27 \\
Inability to feed & 1 & 1.3 \\
\hline
\end{tabular}




\begin{tabular}{|c|c|c|}
\hline Increased poverty level & 46 & 59 \\
Worse standard of living & 1 & 1.3 \\
Worsen poverty level & 9 & 11.5 \\
\hline Total & 78 & 100 \\
\hline
\end{tabular}

Table 3: How Drought Affects the Livelihood of Respondents

Source: (Awosi Et Al., 2018)

\subsection{Livelihood Resilience during Drought Periods}

On the issue of livelihood resilience during drought periods. Many households said their livelihood activities either become poorly resilient $(39 \%)$ or not resilient $(60 \%)$ as indicated in table 4 . When asked if they had any future drought risk management/ investment plan for their households, the answer in totality was in the negative and that they either rely on family relations or household reserves.

\begin{tabular}{|c|c|c|}
\hline Resilience & Frequency & Percentage \\
\hline Very resilient & 0 & 0 \\
Resilient & 1 & 1 \\
Poorly resilient & 39 & 39 \\
Not resilient & 60 & 60 \\
\hline Total & 100 & 100 \\
\hline
\end{tabular}

Table 4: Livelihood Resilience during Drought Periods

Source: (Awosi Et Al., 2018)

\subsection{Coping with Drought Danger during Drought Periods}

Also, on the issue of coping with drought danger during drought periods. From table 5, 84.0 percent of respondents said they rely on family relatives to survive during drought periods. 5.0 percent who were mostly government workers seek external support in the form of loans. Also, 3.0 percent and 7.0 percent of the respondents rely on household reserves and other livelihood supporting activities like mason, migrating to the cities, petty trading etc. respectively.

\begin{tabular}{|c|c|c|}
\hline Coping Strategy & Frequency & Percentage \\
\hline Rely on relatives & 84 & 84.0 \\
Seek external support & 5 & 5.0 \\
Rely on household reserves & 3 & 3.0 \\
Seek divine intervention & 1 & 1.0 \\
Others & 7 & 7.0 \\
\hline Total & 100 & 100.0 \\
\hline
\end{tabular}

Table 5: Coping With Drought Danger during Drought Periods Source: (Awosi Et Al., 2018)

\section{Discussion of Results}

Farming within rural communities of Africa loses prominence during drought periods because it is rain fed. As farming, the main economic driver, comes to a halt, other livelihood opportunities have to be sought for survival during drought periods. While rural livelihood support systems may vary among countries, the choosing of coping strategies during periods of drought is apparent. Evidence from this study shows that rural households resort to different coping strategies during drought periods. Some especially women engage in petty trading, hairdressing and seam stressing while their men counterparts often migrate to the cities to do manual work to support their families through remittances in the absence of opportunities to work as masons and carpenters within their communities. This finding is supported by Cleaver (2002), who argues that women are powerful agents of change, adapting more quickly to new situations than men, and more easily finding alternative means of survival. Evidence from this study confirms women's commitments to explore their immediate environment to support the needs of their households during drought. However, it is unclear why most men resort to out-migration during drought periods. Perhaps men migrate to the cities because carpentry and masonry are less marketable within their communities or out-migration enhances their socio-economic status.

It was also evident from this study that women worked longer hours than men during drought periods. Wives spent daily average time of 13-16 hours working compare to 4-6 hours for husbands. Also, during non-drought periods wives and husband spent between 10-14 hours and 6-10 hours respectively. Thus, generally women continue to be responsible for making sure that children are fed, healthy and educated by working longer hours than men during both drought and non-drought periods. Generally, it is perceived to be customarily wrong for wives in the study area to either ask or challenge husbands to engage in reproductive work to lessen their workload. The researcher observed in the study area that culturally, women are the ones who mostly buy and sell in the local market, and are responsible for household chores. The extent to which men who migrate contribute resources to support the needs of the households they leave behind during drought periods is questionable. This finding is in line with the argument of Moser (2007), where he maintains that men in search of green pastures migrate to the cities for odd jobs and send money and food to women and children they leave behind. However, according to Harris (1981), men as household heads are incapable of meeting the needs of the household because their interest may not lie within the households to which they belong, due to social and 
political reasons. In evidence of this assertion, women in this study said their husbands find new concubines or partners when they migrate to the cities, spend their incomes on these new relationships and lack interest in supporting their families back home. The situation suggests that rural men migrating to urban centres to work during drought periods may put women and children at risk of depending on the meagre incomes of mothers.

Not only can men's seasonal migration be economically unfavourable to their rural households, but it can also pose health risks. Migrant men, through unhealthy sexual practices, can contract HIV/ AIDS and other sexually transmitted diseases which can in turn be transmitted to their innocent wives on their return. Therefore, an alternative to migration that would allow rural men stay and work within their communities during drought periods is most likely to benefit women and their children and rural people at large.

Irrigation facilities that support all-year farming are certainly needed in rural farming communities that experience drought. It was not surprising that women in this study were quick to ask for irrigation facilities to remedy drought situations. The women emphasized that the sale of vegetables cultivated on irrigated lands during drought periods can produce more income and enable their households to have three square meals daily.

Though, the government and few NGOs have provided clean water to most of the communities but had not offered irrigational facilities to these communities. In the absence of irrigation, the rural people are left to fend for themselves during drought periods.

\section{Conclusion}

It was established that the people collect and value most natural assets/ capital such as land, water, livestock, trees etc in the Nandom District. Similarly, the study concluded that it was very difficult for them to collect these assets during drought periods. The study further concluded that households in the Nandom District rely on family relatives to survive during drought periods whiles few households, who were mostly government workers, seek external support in the form of loans. Also, some of the residents rely on household reserves and other livelihood supporting activities like mason, migration to cities, and petty trading during drought periods.

\section{Recommendations}

The implementers of Water Supply Projects should have included irrigation component. Development interventions initiated by both national and international governmental and non-governmental organizations need to begin with need assessments that apply rural appraisal techniques such as matrix scoring and group mapping to allow beneficiaries, both women and men, to include their real needs into the process. Also, development projects, and in this case the WSPs, need to be evaluated periodically - perhaps every four years - to determine and address other emerging realneeds of the beneficiaries. The District Assembly should incorporate drought occurrence into their Medium-Term Development Plan, and promote the coordination of relief and livelihood support initiatives both from government and non-governmental organizations. Dissemination of weather information in the local languages using local radio stations and information vans regarding the ideal time to cultivate crops, the duration of the season, the occurrence of drought in particular, the coping strategies people should adopt should be given priority.

\section{References}

i. Alfredo, K., (2007). Weather Patterns in Northern Ghana. Ghana web: country information. Retrieved from http:/ / www.ghanaweb.com/ GhanaHomePage/ geography/ climate.php.

ii. Bryant, E., A., (1991). "Natural Hazards," Cambridge University Press.

iii. Cleaver, E., (2002). Assessing women contribution to change. The case for asset accumulation. Washington, D.C.: Brookings Institution Press.

iv. Ellis, F., (2000). Rural Livelihoods and Diversity in Developing Countries. Oxford, New York: Oxford University Press.

v. Food and Agricultural Organization (2011). "The state of food and agriculture 2010-2011-Women in agriculture: Closing the gender gap for development. Rome," Food and Agriculture Organization of the United Nations. Retrieved from http:/ / www.fao.org/ docrep/ 013/i2050e/ i2050e00.htm.

vi. Hendy, S. (2001). Effects of drought on crop production in Northern Kenya. Kenya Journal Meteorological services, $43(5), 27-46$.

vii. Inter-governmental Panel on Climate Change (2007). "Contribution of working groups I, II and III to the fourth assessment report of the Inter-governmental Panel on Climate Change, " Geneva, Switzerland: Inter-governmental Panel on Climate Change. Retrieved from http:/ / www.ipcc.ch/ publications and data/ ar4/ syr/ en/ contents.html.

viii. Keane, J., Page, S., Kergna, A., and Kennan J., (2009). "Climate change and developing country agriculture: An overview of expected impacts, adaptation and mitigation challenges, and funding requirements." ICTSD-IPC Platform on Climate Change, Agriculture and Trade, Issue Brief No.2. Geneva, Switzerland: International Centre for Trade and Sustainable Development, and Washington, D.C.: International Food and Agricultural Trade Policy Council. Retrieved from http:/ / www.agritrade.org/ Publications/ documents/JKEANEweb_FINAL.pdf.

ix. Lingnule, T., (2010). The impact of irrigation dams on the livelihoods of farmers in the Upper West Region, Ghana. Livelihoods and climate change, 7 (3), 14-18.

x. Little, E., (2006). Drought effects on livestock production among the poor. A case study. Ehiopia. Poverty and climate change, 4 (2), 16-33.

xi. Long, P., (1977). From accessing to assessing forecasts: A study on economic conditions and climate change in Northern Ghana, West Africa. Climatic Change, 92 (4), 43-46. 
xii. Mohammed, A., (2013). The effects of poverty on the rural dweller in Northern Ghana. Unpublished Mphil thesis; Kumasi, Ghana; Kwame Nkrumah University for Science and Technology.

xiii. Nelson, G., C., (2010). "Food security, farming, and climate change to 2050: Scenarios, results, policy options." Washington, D.C.: International Food Policy Research Institute. Retrieved from http:/ / www.ifpri.org/ sites/ default/ files/ publications/ ib66.pdf.

xiv. Smit, B., Burton, I., Klein, R.., J., T., and Street, R., (1999). "The Science of Adaptation: A Framework for Assessment." Mitigation and Adaptation Strategies for Global Change, 4, 299 - 213.

xv. Verner, D., (2011). "Social implications of climate change in Latin America and the Caribbean." Economic Premise Note 61. Washington, D.C.: The World Bank. Retrieved from

http:/ / siteresources.worldbank.org/ INTPREMNET/ Resources/ EP61.pdf. 